\title{
New Insights Into the Role of Autoreactive CD8 T Cells and Cytokines in Human Type 1 Diabetes
}

\author{
Christine Bender ${ }^{\ddagger}$, Sakthi Rajendran ${ }^{\dagger \neq}$ and Matthias G. von Herrath ${ }^{*}$ \\ Center for Autoimmunity and Inflammation, Type 1 Diabetes Center at La Jolla Institute for Immunology, La Jolla, CA, United States
}

\section{OPEN ACCESS}

Edited by:

Todd M. Brusko,

University of Florida, United States

Reviewed by:

Guido Sebastiani,

University of Siena, Italy

Eddie A. James,

Benaroya Research Institute,

United States

Francesco Dotta,

University of Siena, Italy

Stuart lan Mannering,

University of Melbourne, Australia

*Correspondence:

Matthias G. von Herrath matthias@lij.org

${ }^{\dagger}$ Present Address:

Sakthi Rajendran,

Nationwide Children's Hospital,

Columbus, United States

${ }^{\ddagger}$ These authors have contributed equally to this work

Specialty section:

This article was submitted to

Diabetes: Molecular Mechanisms,

a section of the journal

Frontiers in Endocrinology

Received: 14 September 2020

Accepted: 20 November 2020

Published: 05 January 2021

Citation:

Bender C, Rajendran S and von Herrath MG (2021) New

Insights Into the Role of Autoreactive

CD8 T Cells and Cytokines

in Human Type 1 Diabetes.

Front. Endocrinol. 11:606434. doi: 10.3389/fendo.2020.606434
Since the establishment of the network for pancreatic organ donors with diabetes (nPOD), we have gained unprecedented insight into the pathology of human type 1 diabetes. Many of the pre-existing "dogmas", mostly derived from studies of animal models and sometimes limited human samples, have to be revised now. For example, we have learned that autoreactive CD8 T cells are present even in healthy individuals within the exocrine pancreas. Furthermore, their "attraction" to islets probably relies on beta-cell intrinsic events, such as the over-expression of $\mathrm{MHC}$ class I and resulting presentation of autoantigens such as (prepro)insulin. In addition, we are discovering other signs of betacell dysfunction, possibly at least in part due to stress, such as the over-expression of certain cytokines. This review summarizes the latest developments focusing on cytokines and autoreactive CD8 T cells in human type 1 diabetes pathogenesis.

Keywords: type 1 diabetes, autoreactive CD8 T cells, human pancreas, beta cells, cytokines

\section{INTRODUCTION}

Type 1 diabetes (T1D) is a T cell-mediated autoimmune disease in which the pancreatic insulinsecreting beta cells are selectively destroyed. From decades of T1D studies performed in mice, profound insulitis was thought to be a common feature of T1D. However, with more extensive recent histological studies in the human pancreata, it is evident that insulitis is not that pronounced in patients with T1D (1). Autoreactive CD8 and CD4 T cells are critical players in beta-cell destruction (2) as they recognize peptides of beta-cell antigens that include (pro)insulin and its precursor preproinsulin (PPI), tyrosine phosphatase-like insulinoma antigen (IA-2), islet-specific glucose-6-phosphate catalytic subunit-related protein (IGRP), glutamic acid decarboxylase-65 (GAD65), zinc transporter protein 8 (ZnT8), and islet amyloid polypeptide (IAPP) (3-9). While autoreactive CD8 T cells are activated through interaction with peptides presented by HLA class I (e.g., HLA-A*02:01, $-A^{\star} 24: 02$, and $\left.-B^{\star} 39: 06\right)(3,6,10), C D 4 T$ cells recognize peptides presented by HLA class II molecules (e.g., HLA-DR4, -DQ8) $(8,11,12)$. However, it remains unexplored how they cooperate in islet destruction during T1D development as visualizing $\mathrm{T}$ cell responses in the human pancreas in vivo remains challenging. Nevertheless, mouse studies suggest that $\mathrm{CD} 4 \mathrm{~T}$ cells provide help to effector $\mathrm{CD} 8 \mathrm{~T}$ cells, stimulate antibody production by B cells, and activate islet-resident macrophages $(13,14)$. In addition, intravital two-photon microscopy in a mouse model of autoimmune diabetes indicates a crucial role of CD4 T helper cells in sustaining effector functions of cytotoxic CD8 $\mathrm{T}$ cells at target sites (13).

It is not clearly known what microenvironmental cues drive autoreactive $\mathrm{T}$ cells near the islets in the context of T1D. It is thought that factors such as cytokines, chemokines, oxidative stress, and 
altered antigen presentation may stimulate CD8 T cells, which were previously ignoring self-antigens, to activate and expand. The fact that the autoreactive $\mathrm{T}$ cells are also present in the pancreata of healthy donors (15) suggests a possibility of a triggering event in beta cells, which leads to the recruitment of these cells to the islets in T1D. In this review, we will discuss beta cell-intrinsic events that may increase the visibility of beta cells to the immune system and contribute to the recruitment of autoreactive $\mathrm{T}$ cells to the islets.

\section{MINI-REVIEW}

\section{What Distinguishes T1D Patients From Healthy Individuals?}

For several years, researchers studied T cell responses against islet and beta-cell antigens in peripheral blood to find signatures that differentiate between T1D patients and healthy individuals. Initial studies suggested that autoreactive T cells escape negative selection $(16,17)$ in the thymus and are released into the peripheral blood in patients with T1D, but not in healthy individuals. Then, they get activated by antigen-presenting cells in the draining lymph nodes, which present epitopes derived from islet antigens. This hypothesis was supported by the linkage of polymorphism in the INS gene locus that determines the level of insulin expression in the thymus (17). However, many studies showed that autoreactive T cells are present in healthy individuals' peripheral blood $(4,6)$, refuting the belief that autoreactive $\mathrm{T}$ cells escape negative selection only in T1D patients. Thus, it raises the question of whether the frequencies of such autoreactive $\mathrm{T}$ cells in peripheral blood can help identify patients with T1D. Indeed, higher frequencies of circulating beta-cell specific $\mathrm{CD} 8 \mathrm{~T}$ cells were detected in HLA-A ${ }^{\star} 02: 01^{+}$or HLA-A ${ }^{\star} 24: 02^{+}$subjects with T1D compared with healthy donors $(3,7)$. Among them, PPI-reactive CD8 T cells were more frequently found in T1D patients than in healthy donors $(4,5,7)$. On the other hand, other studies demonstrated no significant differences between T1D and control individuals in the frequencies of circulating CD8 T cells reactive to multiple $\mathrm{A}^{\star} 02: 01$-restricted beta-cell epitopes $\left(\mathrm{PPI}_{14-25}\right.$, $\mathrm{PPI}_{6-14}, \mathrm{InsB}_{10-18}, \mathrm{GAD}_{114-123}, \mathrm{IA-} 2_{797-805}, \mathrm{IA}-2_{805-813}, \mathrm{IGRP}_{265-}$ 273, ZnT8 186-194) $(3,4,6,10)$. However, beta cell-specific CD8 T cells are more differentiated in patients with newly diagnosed T1D compared to healthy controls (6), and memory T cell subsets were enriched within $\mathrm{PPI}_{5-12}$-specific CD8 $\mathrm{T}$ cell populations in HLA$\mathrm{B}^{\star} 39: 06^{+}$children with newly diagnosed T1D, but not in healthy control subjects (10). Overall, these studies suggest that phenotypic subset analysis of such circulating autoreactive $\mathrm{T}$ cells could help to identify patients with T1D.

\section{The Presence of Autoreactive CD8 T Cells in the Target Organ}

The primary critique of studies performed using peripheral blood is that the relationship between tissue-infiltrating and circulating autoreactive CD8 T cells is poorly defined. Many studies of postmortem samples of pancreata revealed the dominant presence of CD8 $\mathrm{T}$ cells in donors with T1D and healthy pancreas (18-20). Using HLA class-I tetramers, Coppieters et al. provided the first proof that $\mathrm{CD} 8 \mathrm{~T}$ cells reactive against IGRP $_{265-273}$, IA-2 $297-805$, and PPI ${ }_{15-24}$ could be found in situ in the islets from individuals with recent-onset and long-standing T1D (21). In these cases, it appeared that early after diagnosis, the islets contained CD8 $\mathrm{T}$ cells specific for one particular autoantigen, whereas, in patients with long-standing T1D, those islets with insulitis showed $\mathrm{T}$ cells with multiple specificities. Building on these findings, Bender et al. further examined the precise localization of $\mathrm{PPI}_{15-24}$-reactive $\mathrm{CD} 8 \mathrm{~T}$ cells not only in the pancreas of nPOD donors with T1D but also in autoantibodypositive and healthy controls (15). Notably, the study showed that many $\mathrm{PPI}_{15-24}$-specific CD8 $\mathrm{T}$ cells are present in the exocrine pancreas of healthy donors and donors with autoantibodies supporting the theory of a general leakiness of central tolerance. In T1D patients, these cells were not only enriched in the exocrine pancreas but were also present within the islets or close to the islets (15). The PPI-specific CD8 T cells significantly infiltrated insulincontaining islets suggesting a critical effector mechanism leading to beta-cell destruction. In line with this, in-situ staining of nPOD pancreas sections revealed similar numbers of $\mathrm{ZnT}_{186-194^{-}}$ positive $A^{\star} 02: 01$-restricted cells in the pancreas of healthy and autoantibody-positive donors but enriched in the pancreas of donors with T1D (4). Surprisingly, the frequencies of $\mathrm{PPI}_{15-24^{-}}$ reactive $\mathrm{CD} 8 \mathrm{~T}$ cells detected in the exocrine pancreas were similar irrespective of disease status. Remarkably, many CD8 T cells recognized the PPI ${ }_{15-24}$ epitopes (15). In contrast to previous studies, where less than $1 \%$ of autoreactive CD8 T cells were detected within the peripheral blood $(4,5)$, frequencies in the pancreas are much higher (30-40\%) (15). Besides, the majority of PPI-reactive CD8 T cells in the exocrine pancreas were positive for CD45RO, suggesting an antigen-experienced phenotype.

Besides conventional peptides, CD8 T cells can also recognize post-translationally modified peptides, $\mathrm{IAPP}_{15-17} / \mathrm{IAPP}_{5-10}$, and SCG-009186-194 generated by mRNA splicing and transpeptidation, respectively (9). Gonzalez-Duque et al. revealed an enriched presence of $\mathrm{IAPP}_{15-17} / \mathrm{IAPP}_{5-10}$, urocortin

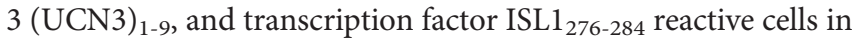
the human pancreas of donors with T1D (9). In comparison, the frequency of these reactive cells was similar between T1D patients and healthy individuals (9).

Although CD8 $\mathrm{T}$ cells are the most predominant immune infiltrates in human insulitis [1], autoreactive CD4 T cells are also involved in the pathogenesis of T1D and CD4 T cell responses to proinsulin, $\mathrm{GAD}$, and IA-2 were identified in the islets of donors with $\operatorname{T1D}(8,22,23)$.

Consequently, what determines the progression of T1D in the face of similar frequencies of autoreactive CD8 T cells? Do betacells respond differently to inflammation that causes the attraction of CD8 T cells? The high numbers of autoreactive CD8 T cells in the pancreas suggest that autoreactivity is physiological and that disease development, therefore, is prevented under normal circumstances by local, organ-specific control mechanisms. Thus, defective organ-specific control mechanisms and/or a proinflammatory islet microenvironment are key pathogenic features of T1D. 


\section{How Stressed Beta Cells Secrete Cytokines That May be Involved in Bringing in Autoreactive T Cells?}

Cytokine and chemokine secretion are broadly implicated as key immune cell recruiting factors in T1D. It is believed that cytokines are typically secreted by immune cells during the pathogenesis of T1D. However, recently mounting evidence suggests that pancreatic islets per se secrete cytokines under physiological conditions or under stress. For instance, IL-6 was shown to be expressed by both beta and alpha cells in nondiabetic and autoantibody-positive individuals, but its expression was reduced in donors with T1D (24). Similarly, alpha cells were shown to express IL-1b in pancreatic tissue sections, irrespective of the diabetes status (25). Cytokines such as IL-6 act at a physiological level in islet cells to maintain glucose homeostasis (26), whereas other cytokines such as IFN- $\gamma$ and CXCL10 may play a pathogenic role by contributing to immune cell recruitment and beta-cell killing. Cytokine receptors such as IL-4R, IL-13R, IL-6R were all shown to be widely expressed by islet cells (27-29), underscoring the possibility of cytokineinduced changes in islet cells that could facilitate immune attack. Here we will discuss some islet-intrinsic factors that may be involved in the recruitment of autoreactive $\mathrm{T}$ cells and secretion of pathogenic cytokines implicated in T1D.

Among the beta cell-intrinsic events, hyperexpression of MHC class I has been considered as a hallmark feature of T1D (30). Homing of autoreactive T cells to islets was inhibited in the absence of MHC class I expression in the NOD model of T1D (31). Treatment of human islets with IFN- $\gamma$ induced MHC class I hyperexpression along with upregulation of chemokines such as CXCL10 in beta cells (32). Multiple reports identify proinflammatory cytokines and viral infection as major inducers of MHC class-I in islets. Although no viral infection has been shown to cause T1D directly, it may be possible that infection of beta cells may induce some islet-intrinsic changes. For instance, human islets upon infection with Coxsackie virus B (CVB) have been shown to secrete increased levels of IL-6, TNF, IP-10, and interferon-stimulated genes (33). Gallagher et al. have attempted to study CVB infection in an islet transplantation model devoid of native beta cells. Transplantation of healthy human islets in these mice reversed hyperglycemia, but this effect was abrogated upon infection of these mice with Coxsackievirus B. Signatures of viral RNA and increased levels of interferon-stimulated genes, CXCL10 and CCL5, could be observed in the transplanted islets (34). These evidence further prove that human islets could be infected with CVB, which could further drive pro-inflammatory factors and chemokines. The enrichment of autoreactive CD8 $\mathrm{T}$ cells near the islets suggests that they become attracted to their key antigen in insulin-containing islets during disease development (15), possibly due to the upregulation of MHC class I (30) and accumulation of target autoantigen (35). However, it is not clearly known whether MHC class I upregulation is responsible for the recruitment of autoreactive $\mathrm{T}$ cells or vice versa.

CXCL10 or IP-10 (IFN- inducible protein-10) is one of the most important cytokines implicated in T1D pathogenesis.
CXCL10 expression could be observed in the beta cells of donors with recent-onset T1D, irrespective of their infection status with enterovirus. CXCR3, the receptor of CXCL10, could also be observed in proinsulin specific $\mathrm{T}$ cells of the T1D patient. In contrast, islets of non-diabetic donors were devoid of both CXCL10 and CXCR3 (36). Another independent study similarly reported that CXCL10 is expressed predominantly on beta cells and not by other endocrine cells in insulin-containing islets of T1D subjects (37). More recently, Nigi et al. have shown CXCL10 expression in alpha cells and beta cells of donors with T1D. Interestingly, insulin-containing islets in T1D had an increased percentage of CXCL10-positive alpha cells compared to CXCL10-positive beta cells suggesting an involvement of alpha cells in chemokine secretion (38). Both CXCL9 and CXCL10 have been shown to be secreted by beta cells in insulitic islets, which drive CXCR3+ autoreactive T cells to islets in the RIP-LCMV model of T1D. The deletion of the CXCR3 gene in these mice has been beneficial in delaying the onset of T1D and insulitis (39). In addition, production of CXCL10 by autoreactive CD8 T cells was shown to be an essential factor in determining the diabetogenicity of CD8 T cell clones (40).

CCL21 has also been reported to be an essential factor for the homing of insulin-specific CD8 T cells to islets and for the interaction of islets with endothelial cells presenting the major auto-antigen, Insulin (31). Ectopic expression of CCL21 in beta cells influenced the recruitment of $\mathrm{T}$ cells, $\mathrm{B}$ cells, and dendritic cells to the islet periphery in a murine T1D model (41). Interestingly, expression of CCL21 by islets in NOD mice protected the mice from T1D; however, these mice still exhibited insulitis with $\mathrm{T}$ cells and fibroblastic reticular cell (FRC)-like cells expressing autoantigen, possibly inducing an antigen-specific immune tolerance (42).

In recent onset cases with T1D, laser capture microdissection studies have shown the overexpression of several interferonstimulated genes such as GBP1, TLR3, HLA-E, and STAT1 transcripts, compared to islets from non-diabetic individuals (43). Single-cell RNA sequencing of human islets revealed that chemokine transcripts were the most up-regulated among other transcripts upon exposure to pro-inflammatory cytokines. This report also confirmed the expression of cytokines and chemokines such as IL-6, IL-8, CCL2, and CXCL10 at the protein level (44). Exposure of human islets to cytokines, especially IL- $1 \beta$ and IFN- $\gamma$, has resulted in increased extracellular accumulation of proinsulin, suggesting its disproportionate conversion of proinsulin to insulin. This evidence points towards the role of cytokines in beta cell dysfunction (45). In contrast, the treatment of human islets with IFN- $\gamma$ and IFN- $\alpha$ in-vitro has resulted in the upregulation of PDL1 by beta cells. PDL1 was also found to be expressed in insulin-containing islets from donors with T1D, but not in nondiabetic controls. Whether this phenomenon is a compensatory mechanism to reduce $\mathrm{T}$ cell activation is yet to be studied (46). Similarly, SOCS (suppressor of cytokine signaling) 1, 2, 3 were all expressed in the islets of donors with T1D, but not in nondiabetic donors. SOCS expression was up-regulated upon exposure of human islets to IFN- $\gamma$, TNF $\alpha$, and IL-1 $\beta$. 
Additionally, the transfection of SOCS1 in beta cells has been reported to inhibit IFN- $\gamma$ signaling and MHC class I hyperexpression (47). This evidence suggests that beta cells could up-regulate SOCS in an attempt to protect the islets from cytokine-induced cell damage (48).

Immunohistochemical studies of donors with T1D revealed increased expression of some components of ER stress, such as $\mathrm{CHOP}$ and BIP, compared to non-diabetic individuals. These components mostly co-stained with insulin (49), implying that beta cells could be undergoing cellular stress during T1D. Human beta cells pre-treated with an ER stress inhibitor, TUDCA resulted in reduced cytokine-induced JNK pathway, IRE1 $\alpha$ (inositol-requiring enzyme $1 \alpha$ ) activity, a key component of unfolded protein response, and apoptosis (50).

Therefore, these events, in addition to other factors leading to islet-attraction of autoreactive CD8 T cells already within the pancreas, may be a crucial mechanism in T1D development.

\section{CONCLUDING QUESTIONS}

In this review, we discussed the evidence that autoreactive CD8 T cells are an integral and large part of the pancreatic leukocyte population in healthy individuals and can be detected in large numbers in donors with T1D (Figure 1). Although autoreactive CD8 T cells are preferentially present in the pancreas, but not in blood of T1D patients, some key questions remain to be addressed.
1. Why are so many CD8 T cells in the exocrine pancreas PPI specific? Is it due to an abundance of this antigen in the pancreas? Could it be that beta-cells are not visible in healthy individuals under physiological conditions, a status termed immunological "ignorance" (51)? What then happens to these cells during disease development?

2. There is growing evidence from mouse and human studies suggesting insulin as the key autoantigen in T1D. But is PPI a "driver" autoantigen in T1D, and are PPI-specific T cells predominantly present in the pancreas of every individual, or does every individual have a different "driver" autoantigen?

3. Does CD8 T cell exhaustion occur in the pancreatic islets (indicated by PD-1 upregulation, and could this be a potential regulatory mechanism)? An exciting study recently demonstrated that islet-specific CD8 T cells of healthy controls and T1D patients comprise three dominant phenotypes that display characteristics of transitional memory and exhausted memory cells (52).

4. To date, less is known about post-translationally spliced peptides that can be recognized by CD8 $\mathrm{T}$ cells in the target organ. One study reported IAPP ${ }_{15-17} /$ IAPP $_{5-10}$ reactive cells in the human pancreas (9), but are there other neoantigens that can be recognized by CD8 T cells?

5. Is cytokine upregulation in beta cells necessarily a pathogenic factor in T1D or a compensatory mechanism to combat cellular stress?

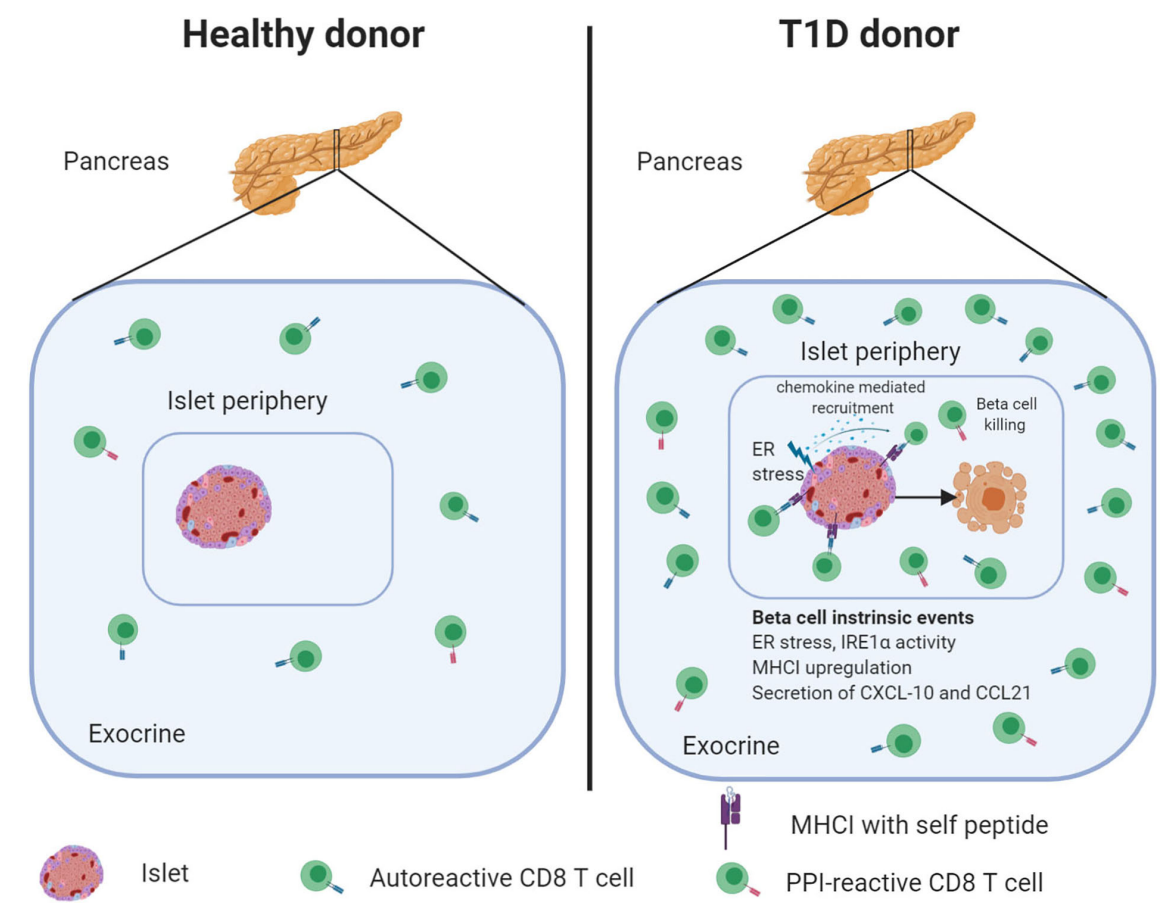

FIGURE 1 | The healthy human pancreas contains autoreactive CD8 T cells that increase in numbers during diabetes development. Frequencies of PPI-specific CD8 T cells are similar in the exocrine pancreas irrespective of disease status. However, during disease progression, PPI-reactive CD8 T cells become attracted to the islets. The secretion of cytokines, under physiological conditions or stress, may contribute to immune cell recruitment and beta-cell killing. Created with BioRender.com. 
To date, antigen-specific therapy for T1D that selectively dampens $\mathrm{T}$ cell responses to main beta-cell proteins remains elusive. One of the major hurdles is the choice of antigens and the timing of therapeutic intervention. Therefore, to design effective and durable immunotherapies for $\mathrm{T} 1 \mathrm{D}$, it is imperative to identify the numbers and phenotype of islet antigen-specific $\mathrm{T}$ cells, specifically in the pancreas, and whether changes in specificities occur over disease progression.

\section{AUTHOR CONTRIBUTIONS}

$\mathrm{CB}$ and SR wrote the manuscript. MV critically reviewed the manuscript. All authors contributed to the article and approved the submitted version.

\section{REFERENCES}

1. Campbell-Thompson M, Fu A, Kaddis JS, Wasserfall C, Schatz DA, Pugliese A, et al. Insulitis and beta-Cell Mass in the Natural History of Type 1 Diabetes. Diabetes (2016) 65:719-31. doi: 10.2337/db15-0779

2. Pugliese A. Autoreactive $\mathrm{T}$ cells in type 1 diabetes. J Clin Invest (2017) 127:2881-91. doi: 10.1172/JCI94549

3. Velthuis JH, Unger WW, Abreu JR, Duinkerken G, Franken K, Peakman M, et al. Simultaneous detection of circulating autoreactive CD8+ T-cells specific for different islet cell-associated epitopes using combinatorial MHC multimers. Diabetes (2010) 59:1721-30. doi: 10.2337/db09-1486

4. Culina S, Lalanne AI, Afonso G, Cerosaletti K, Pinto S, Sebastiani G, et al. Islet-reactive $\mathrm{CD} 8(+) \mathrm{T}$ cell frequencies in the pancreas, but not in blood, distinguish type 1 diabetic patients from healthy donors. Sci Immunol (2018) 3. doi: 10.1126/sciimmunol.aao4013

5. Yu W, Jiang N, Ebert PJ, Kidd BA, Muller S, Lund PJ, et al. Clonal Deletion Prunes but Does Not Eliminate Self-Specific alphabeta CD8(+) T Lymphocytes. Immunity (2015) 42:929-41. doi: 10.1016/j.immuni. 2015.05.001

6. Skowera A, Ladell K, McLaren JE, Dolton G, Matthews KK, Gostick E, et al. beta-cell-specific CD8 $\mathrm{T}$ cell phenotype in type 1 diabetes reflects chronic autoantigen exposure. Diabetes (2015) 64:916-25. doi: 10.2337/db14-0332

7. Kronenberg D, Knight RR, Estorninho M, Ellis RJ, Kester MG, de Ru A, et al. Circulating preproinsulin signal peptide-specific $\mathrm{CD} 8 \mathrm{~T}$ cells restricted by the susceptibility molecule HLA-A24 are expanded at onset of type 1 diabetes and kill beta-cells. Diabetes (2012) 61:1752-9. doi: 10.2337/db11-1520

8. Babon JA, DeNicola ME, Blodgett DM, Crevecoeur I, Buttrick TS, Maehr R, et al. Analysis of self-antigen specificity of islet-infiltrating $\mathrm{T}$ cells from human donors with type 1 diabetes. Nat Med (2016) 22:1482-7. doi: 10.1038/ nm.4203

9. Gonzalez-Duque S, Azoury ME, Colli ML, Afonso G, Turatsinze JV, Nigi L, et al. Conventional and Neo-antigenic Peptides Presented by beta Cells Are Targeted by Circulating Naive CD8+ T Cells in Type 1 Diabetic and Healthy Donors. Cell Metab (2018) 28:946-960 e6. doi: 10.1016/j.cmet.2018.07.007

10. Yeo L, Pujol-Autonell I, Baptista R, Eichmann M, Kronenberg-Versteeg D, Heck S, et al. Circulating beta cell-specific CD8(+) T cells restricted by highrisk HLA class I molecules show antigen experience in children with and at risk of type 1 diabetes. Clin Exp Immunol (2020) 199:263-77. doi: 10.1111/ cei. 13391

11. Neefjes J, Jongsma ML, Paul P, Bakke O. Towards a systems understanding of MHC class I and MHC class II antigen presentation. Nat Rev Immunol (2011) 11:823-36. doi: 10.1038/nri3084

12. Pathiraja V, Kuehlich JP, Campbell PD, Krishnamurthy B, Loudovaris T, Coates PT, et al. Proinsulin-specific, HLA-DQ8, and HLA-DQ8-transdimerrestricted CD4+ T cells infiltrate islets in type 1 diabetes. Diabetes (2015) 64:172-82. doi: 10.2337/db14-0858

13. Espinosa-Carrasco G, Le Saout C, Fontanaud P, Stratmann T, Mollard P, Schaeffer M, et al. CD4(+) T Helper Cells Play a Key Role in Maintaining

\section{FUNDING}

Funding was received from the National Institutes of Health (NIH), grant \# RO1 AI092453 and RO1 AI134971.

\section{ACKNOWLEDGMENTS}

We thank tissue bank organizations for continuously providing pancreas samples and allowing us to improve our knowledge of type 1 diabetes pathology. We thank all the donors and their families who have generously donated organs for research purposes.

Diabetogenic CD8(+) T Cell Function in the Pancreas. Front Immunol (2017) 8:2001. doi: 10.3389/fimmu.2017.02001

14. Burrack AL, Martinov T, Fife BT. T Cell-Mediated Beta Cell Destruction: Autoimmunity and Alloimmunity in the Context of Type 1 Diabetes. Front Endocrinol (Lausanne) (2017) 8:343. doi: 10.3389/fendo.2017.00343

15. Bender C, Rodriguez-Calvo T, Amirian N, Coppieters KT, von Herrath MG. The healthy exocrine pancreas contains preproinsulin-specific CD8 T cells that attack islets in type 1 diabetes. Sci Adv (2020) 6. doi: 10.1126/ sciadv.abc5586

16. Chentoufi AA, Polychronakos C. Insulin expression levels in the thymus modulate insulin-specific autoreactive T-cell tolerance: the mechanism by which the IDDM2 locus may predispose to diabetes. Diabetes (2002) 51:138390. doi: 10.2337/diabetes.51.5.1383

17. Pugliese A, Zeller M, Fernandez A Jr., Zalcberg LJ, Bartlett RJ, Ricordi C, et al. The insulin gene is transcribed in the human thymus and transcription levels correlated with allelic variation at the INS VNTR-IDDM2 susceptibility locus for type 1 diabetes. Nat Genet (1997) 15:293-7. doi: 10.1038/ng0397-293

18. Rodriguez-Calvo T, Ekwall O, Amirian N, Zapardiel-Gonzalo J, von Herrath MG. Increased immune cell infiltration of the exocrine pancreas: a possible contribution to the pathogenesis of type 1 diabetes. Diabetes (2014) 63:388090. doi: $10.2337 / \mathrm{db} 14-0549$

19. Willcox A, Richardson SJ, Bone AJ, Foulis AK, Morgan NG. Analysis of islet inflammation in human type 1 diabetes. Clin Exp Immunol (2009) 155:17381. doi: 10.1111/j.1365-2249.2008.03860.x

20. Weisberg SP, Carpenter DJ, Chait M, Dogra P, Gartrell-Corrado RD, Chen AX, et al. Tissue-Resident Memory T Cells Mediate Immune Homeostasis in the Human Pancreas through the PD-1/PD-L1 Pathway. Cell Rep (2019) 29:3916-32.e5. doi: 10.1016/j.celrep.2019.11.056

21. Coppieters KT, Dotta F, Amirian N, Campbell PD, Kay TW, Atkinson MA, et al. Demonstration of islet-autoreactive CD8 T cells in insulitic lesions from recent onset and long-term type 1 diabetes patients. J Exp Med (2012) 209:5160. doi: 10.1084/jem.20111187

22. Michels AW, Landry LG, McDaniel KA, Yu L, Campbell-Thompson M, Kwok WW, et al. Islet-Derived CD4 T Cells Targeting Proinsulin in Human Autoimmune Diabetes. Diabetes (2017) 66:722-34. doi: 10.2337/db16-1025

23. Spanier JA, Sahli NL, Wilson JC, Martinov T, Dileepan T, Burrack AL, et al. Increased Effector Memory Insulin-Specific CD4(+) T Cells Correlate With Insulin Autoantibodies in Patients With Recent-Onset Type 1 Diabetes. Diabetes (2017) 66:3051-60. doi: 10.2337/db17-0666

24. Rajendran S, Anquetil F, Quesada-Masachs E, Graef M, Gonzalez N, McArdle S, et al. IL-6 is present in beta and alpha cells in human pancreatic islets: Expression is reduced in subjects with type 1 diabetes. Clin Immunol (2020) 211:108320. doi: 10.1016/j.clim.2019.108320

25. Anquetil F, Sabouri S, Thivolet C, Rodriguez-Calvo T, Zapardiel-Gonzalo J, Amirian N, et al. Alpha cells, the main source of IL-1beta in human pancreas. J Autoimmun (2017) 81:68-73. doi: 10.1016/j.jaut.2017.03.006

26. Ellingsgaard H, Ehses JA, Hammar EB, Van Lommel L, Quintens R, Martens G, et al. Interleukin- 6 regulates pancreatic alpha-cell mass expansion. 
Proc Natl Acad Sci U S A (2008) 105:13163-8. doi: 10.1073/pnas.0801 059105

27. Rajendran S, Graef M, Chu T, von Herrath M. IL-4R is expressed on alpha and beta cells of human pancreata. Clin Immunol (2020) 214:108394. doi: 10.1016/ j.clim.2020.108394

28. Russell MA, Morgan NG. The impact of anti-inflammatory cytokines on the pancreatic beta-cell. Islets (2014) 6:e950547. doi: 10.4161/19382014. 2014.950547

29. Kaminski A, Welters HJ, Kaminski ER, Morgan NG. Human and rodent pancreatic beta-cells express IL-4 receptors and IL-4 protects against beta-cell apoptosis by activation of the PI3K and JAK/STAT pathways. Biosci Rep (2009) 30:169-75. doi: 10.1042/BSR20090021

30. Richardson SJ, Rodriguez-Calvo T, Gerling IC, Mathews CE, Kaddis JS, Russell MA, et al. Islet cell hyperexpression of HLA class I antigens: a defining feature in type 1 diabetes. Diabetologia (2016) 59:2448-58. doi: 10.1007/s00125-016-4067-4

31. Savinov AY, Wong FS, Stonebraker AC, Chervonsky AV. Presentation of antigen by endothelial cells and chemoattraction are required for homing of insulin-specific CD8+ T cells. J Exp Med (2003) 197:643-56. doi: 10.1084/ jem. 20021378

32. Marroqui L, Dos Santos RS, Op de Beeck A, Coomans de Brachene A, Marselli L, Marchetti P, et al. Interferon-alpha mediates human beta cell HLA class I overexpression, endoplasmic reticulum stress and apoptosis, three hallmarks of early human type 1 diabetes. Diabetologia (2017) 60:656-67. doi: 10.1007/ s00125-016-4201-3

33. Schulte BM, Lanke KH, Piganelli JD, Kers-Rebel ED, Bottino R, Trucco M, et al. Cytokine and chemokine production by human pancreatic islets upon enterovirus infection. Diabetes (2012) 61:2030-6. doi: 10.2337/db11-1547

34. Gallagher GR, Brehm MA, Finberg RW, Barton BA, Shultz LD, Greiner DL, et al. Viral infection of engrafted human islets leads to diabetes. Diabetes (2015) 64:1358-69. doi: 10.2337/db14-1020

35. Rodriguez-Calvo T, Zapardiel-Gonzalo J, Amirian N, Castillo E, Lajevardi Y, Krogvold L, et al. Increase in Pancreatic Proinsulin and Preservation of betaCell Mass in Autoantibody-Positive Donors Prior to Type 1 Diabetes Onset. Diabetes (2017) 66:1334-45. doi: 10.2337/db16-1343

36. Roep BO, Kleijwegt FS, van Halteren AG, Bonato V, Boggi U, Vendrame F, et al. Islet inflammation and CXCL10 in recent-onset type 1 diabetes. Clin Exp Immunol (2010) 159:338-43. doi: 10.1111/j.1365-2249.2009.04087.x

37. Uno S, Imagawa A, Saisho K, Okita K, Iwahashi H, Hanafusa $T$, et al. Expression of chemokines, CXC chemokine ligand 10 (CXCL10) and CXCR3 in the inflamed islets of patients with recent-onset autoimmune type 1 diabetes. Endocrine J (2010) 57:991-6. doi: 10.1507/endocrj.K10E-076

38. Nigi L, Brusco N, Grieco GE, Licata G, Krogvold L, Marselli L, et al. Pancreatic Alpha-Cells Contribute Together With Beta-Cells to CXCL10 Expression in Type 1 Diabetes. Front Endocrinol (Lausanne) (2020) 11:630. doi: 10.3389/ fendo.2020.00630

39. Frigerio S, Junt T, Lu B, Gerard C, Zumsteg U, Hollander GA, et al. Beta cells are responsible for CXCR3-mediated T-cell infiltration in insulitis. Nat Med (2002) 8:1414-20. doi: 10.1038/nm1202-792

40. Ejrnaes M, Videbaek N, Christen U, Cooke A, Michelsen BK, von Herrath M. Different diabetogenic potential of autoaggressive CD8+ clones associated with IFN-gamma-inducible protein 10 (CXC chemokine ligand 10) production but not cytokine expression, cytolytic activity, or homing characteristics. J Immunol (2005) 174:2746-55. doi: 10.4049/jimmunol.174.5.2746

41. Chen SC, Vassileva G, Kinsley D, Holzmann S, Manfra D, Wiekowski MT, et al. Ectopic expression of the murine chemokines CCL21a and CCL21b induces the formation of lymph node-like structures in pancreas, but not skin, of transgenic mice. J Immunol (2002) 168:1001-8. doi: 10.4049/ jimmunol.168.3.1001

42. Gonzalez Badillo FE, Zisi Tegou F, Abreu MM, Masina R, Sha D, Najjar M, et al. CCL21 Expression in beta-Cells Induces Antigen-Expressing Stromal Cell Networks in the Pancreas and Prevents Autoimmune Diabetes in Mice. Diabetes (2019) 68:1990-2003. doi: 10.2337/db19-0239

43. Lundberg M, Krogvold L, Kuric E, Dahl-Jorgensen K, Skog O. Expression of Interferon-Stimulated Genes in Insulitic Pancreatic Islets of Patients Recently Diagnosed With Type 1 Diabetes. Diabetes (2016) 65:3104-10. doi: 10.2337/ db16-0616

44. Eizirik DL, Sammeth M, Bouckenooghe T, Bottu G, Sisino G, Igoillo-Esteve $\mathrm{M}$, et al. The human pancreatic islet transcriptome: expression of candidate genes for type 1 diabetes and the impact of pro-inflammatory cytokines. PloS Genet (2012) 8:e1002552. doi: 10.1371/journal.pgen.1002552

45. Hostens K, Pavlovic D, Zambre Y, Ling Z, Van Schravendijk C, Eizirik DL, et al. Exposure of human islets to cytokines can result in disproportionately elevated proinsulin release. J Clin Invest (1999) 104:67-72. doi: 10.1172/ JCI6438

46. Colli ML, Hill JLE, Marroqui L, Chaffey J, Dos Santos RS, Leete P, et al. PDL1 is expressed in the islets of people with type 1 diabetes and is up-regulated by interferons-alpha and-gamma via IRF1 induction. EBioMedicine (2018) 36:367-75. doi: 10.1016/j.ebiom.2018.09.040

47. Chong MM, Thomas HE, Kay TW. gamma-Interferon signaling in pancreatic beta-cells is persistent but can be terminated by overexpression of suppressor of cytokine signaling-1. Diabetes (2001) 50:2744-51. doi: 10.2337/ diabetes.50.12.2744

48. Santangelo C, Scipioni A, Marselli L, Marchetti P, Dotta F. Suppressor of cytokine signaling gene expression in human pancreatic islets: modulation by cytokines. Eur J Endocrinol (2005) 152:485-9. doi: 10.1530/eje.1.01856

49. Marhfour I, Lopez XM, Lefkaditis D, Salmon I, Allagnat F, Richardson SJ, et al. Expression of endoplasmic reticulum stress markers in the islets of patients with type 1 diabetes. Diabetologia (2012) 55:2417-20. doi: 10.1007/ s00125-012-2604-3

50. Brozzi F, Nardelli TR, Lopes M, Millard I, Barthson J, Igoillo-Esteve M, et al. Cytokines induce endoplasmic reticulum stress in human, rat and mouse beta cells via different mechanisms. Diabetologia (2015) 58:2307-16. doi: 10.1007/ s00125-015-3669-6

51. Dissanayake D, Gronski MA, Lin A, Elford AR, Ohashi PS. Immunological perspective of self versus tumor antigens: insights from the RIP-gp model. Immunol Rev (2011) 241:164-79. doi: 10.1111/j.1600-065X.2011.01014.x

52. Wiedeman AE, Muir VS, Rosasco MG, DeBerg HA, Presnell S, Haas B, et al. Autoreactive CD8+ T cell exhaustion distinguishes subjects with slow type 1 diabetes progression. J Clin Invest (2020) 130:480-90. doi: 10.1172/ JCI126595

\section{Conflict of Interest: MV is an employee of Novo Nordisk.}

The remaining author declares that the research was conducted in the absence of any commercial or financial relationships that could be construed as a potential conflict of interest.

Copyright (c) 2021 Bender, Rajendran and von Herrath. This is an open-access article distributed under the terms of the Creative Commons Attribution License (CC BY). The use, distribution or reproduction in other forums is permitted, provided the original author(s) and the copyright owner(s) are credited and that the original publication in this journal is cited, in accordance with accepted academic practice. No use, distribution or reproduction is permitted which does not comply with these terms. 